\title{
Los trasplantes institucionales en el campo del derecho. Una nueva perspectiva para la nueva economía institucional
}

\author{
Sara BLANCO CONTRERAS \\ Universidad Rey Juan Carlos \\ sara.blanco.contreras@madrid.org
}

Received: 05/08/2016

Accepted: 02/11/2016

\begin{abstract}
Resumen
La Nueva Economía Institucional (NEI) comenzó recientemente a plantearse la utilidad de los trasplantes institucionales como medio para promover el crecimiento económico. Sin embargo, pronto se dieron cuenta de que estos trasplantes en general fallaban debido al problema del path dependence, que provocaba el choque de la institución formal trasplantada con las instituciones informales de la sociedad receptora. ¿Son estos trasplantes institucionales algo nuevo o, por el contrario, son un fenómeno importado de otra disciplina? En este artículo analizamos el origen de los trasplantes, aportando una visión enteramente jurídica del tema a través de los trabajos de los principales juristas que han estudiado esta materia en el campo del Derecho -especialmente dentro del Derecho comparado-.
\end{abstract}

Palabras clave: Nueva Economía Institucional, trasplantes institucionales, path dependence, Derecho, Derecho comparado

Clasificación JEL: B5; K0; K3

Institutional transplants in the field of Law. A new view for New Institutional Economics

\begin{abstract}
New Institutional Economics (NIE) recently started to consider the usefulness of institutional transplants as a means of stimulating economic growth. However, they soon realised that these transplants generally failed due to the "path dependence" issue that caused the collision of the formal transplanted institution with the informal institutions of the host society. Are these institutional transplants something new or, on the contrary, are they a phenomenon imported from other discipline? In this article we analyse the origin of the transplants, providing an entirely legal view of the subject through the work of the jurists that have mainly studied this matter in the field of Law -especially in Comparative Law-.
\end{abstract}

Keywords: New Institutional Economics, institutional transplants, path dependence, Law, Comparative Law

JEL Classification: B5; K0; K3

\section{Introducción}

Muchos economistas, en su mayoría representantes de la Nueva Economía Institucional (en adelante NEI), creen que una nación con unas instituciones adecuadas y con una estructura de poder que las haga cumplir, unida a una cultura de cumplimiento de las normas por parte de los ciudadanos, conseguirá un desarrollo económico sostenido. Partiendo de esta hipótesis, los países que necesiten crecer podrían tomar prestadas normas, doctrinas o prácticas que han supuesto un éxito en su país de origen, introducirlas en su ordenamiento jurídico y conseguir con ello mejorar su desempeño económico.

Inicialmente la NEI no prestó atención a los trasplantes institucionales ni a sus posibles limitaciones causadas por factores sociales o intereses políticos. Pero al observar como fracasaban una y otra vez los intentos de generar crecimiento por parte de algunos países y organizaciones internacionales, diversos economistas empezaron a analizar la posibilidad de que, realizando una reforma en esos países a través de trasplantes, se pudiera conseguir su despegue económico. Sin embargo, no existen apenas estudios en el campo de la economía, y en concreto en el de la NEI, que analicen este fenómeno. Y desde luego, los autores pertenecientes a esta disciplina 
generalmente desconocen que, en el campo del Derecho, sobre todo en el Derecho comparado, sí existe numerosa literatura al respecto.

Lo que sí han analizado, y de forma extensa, diversos economistas relacionados con la NEI como Daron Acemoglu, James Robinson o Mancur Olson, son las causas del crecimiento económico. La NEI cree que las razones que explican el crecimiento no son los factores geográficos o la acumulación de capital porque esos factores son el crecimiento mismo. Para esta disciplina, la principal causa del crecimiento económico son las instituciones con que cuente cada país. Esta teoría es perfectamente compatible con la idea de que un trasplante institucional puede generar crecimiento económico. Este ha sido, precisamente, uno de los objetivos de algunas agencias internacionales, como el Banco Mundial o el Fondo Monetario Internacional (FMI), a la hora de conceder préstamos condicionados a la adopción, por medio de trasplantes, de normas o instituciones consideradas "buenas" por la comunidad internacional. Estos programas de desarrollo basados en reformas legales han fallado una y otra vez, lo que implica que el trasplante institucional no ha funcionado. ¿Es, por tanto, imposible el trasplante de normas de un ordenamiento jurídico a otro? ¿O es que el trasplante falla por otras razones?

En este artículo veremos que, tratando de responder a estas preguntas, numerosos autores, sobre todo en el campo del Derecho comparado, han desarrollado teorías sobre esta materia e incluso han hecho estudios de casos. El repaso de esta literatura sobre trasplantes desde la perspectiva del Derecho es nuestra principal aportación, dado que estos estudios son generalmente desconocidos en el campo de la NEI. Los diferentes resultados de estas investigaciones jurídicas sobre trasplantes, que se remontan a la década de los años 70 del siglo pasado, reflejan las dos posturas tradicionales que ha habido en la literatura sobre difusión del Derecho. Algunos autores han encontrado numerosos casos en los que un determinado trasplante ha funcionado. Así, por ejemplo, el historiador del Derecho Alan Watson aboga por los trasplantes como principal forma de desarrollo del Derecho en el mundo. Ciertos académicos, como Mathias M. Siems, aseguran incluso que hay casos en los que la norma trasplantada ha funcionado mejor en el país receptor que en el de origen. Sin embargo, para otros académicos, el trasplante es imposible o falla debido, en la gran mayoría de los casos, a que la cultura de la sociedad en la que se trasplanta la regla no es la misma que la de la sociedad del país donde esta regla se originó. Aquí entra en juego el llamado path dependence, que hace referencia al camino que van creando a lo largo de los años las instituciones informales -tradiciones, creencias, valores, etc.- de una determinada sociedad y a la dificultad de desviarse de esa senda una vez marcada. Por eso, cuando se intenta trasplantar una institución formal a una sociedad con instituciones informales no compatibles, es muy probable que el trasplante falle. Defensores de esta última postura son Pierre Legrand, para el que los trasplantes son imposibles, y Otto Kahn-Freund, entre otros. En la terminología usada por la jurista Margit Cohn, a los defensores de los trasplantes se les conoce como transferists o "transferistas" y a sus detractores como culturalists o "culturalistas". Un ejemplo de culturalista histórico es Montesquieu, que ya en el siglo XVIII veía muy complicado el traslado de normas de un sistema legal a otro.

Hace unas décadas hubo un resurgimiento del interés práctico y académico relativo a la reforma legal y a la armonización como parte de la integración europea, los programas de ajuste estructural en los países en vías de desarrollo y la reconstrucción de los países en transición de Europa del este. Más recientemente este creciente interés ha tenido que ver con el fenómeno de la globalización, que ha estimulado los trasplantes legales al hacer que tomar prestadas prácticas o instituciones de otro país sea más común. Sin embargo, y a pesar de que a los neoinstitucionalistas les han empezado a interesar hace muy poco, los trasplantes de normas han existido siempre en la historia de la humanidad. Tanto es así que algunos autores, como el citado Alan Watson, afirman que los trasplantes son el medio principal por el que las leyes han ido evolucionando en el mundo. Como veremos, los estudios jurídicos sobre trasplantes han sido fundamentalmente académicos, pero en los últimos tiempos existe también una línea de investigación práctica que examina su éxito o fracaso en casos concretos. El concepto de "éxito" es impreciso en la literatura pero, en general, podemos decir que un trasplante ha funcionado si la norma importada sobrevive un periodo de tiempo considerable en el país receptor. 
El objetivo principal de este artículo, por tanto, es proporcionar a los representantes de la Nueva Economía Institucional otra perspectiva del fenómeno de los trasplantes institucionales, poniendo de manifiesto la extensa literatura que existe sobre este tema en ciertas disciplinas del Derecho, sobre todo Derecho comparado y Law and Economics (Análisis Económico del Derecho). Para ello, comenzaremos definiendo el concepto de "trasplante institucional" desde un punto de vista jurídico. A continuación, citaremos brevemente lo que se ha dicho en el campo de la economía en relación a este fenómeno, incluyendo algunos estudios sobre la relación entre estas reformas legales a través de trasplantes y el crecimiento económico. Por último, analizaremos las dos posturas tradicionales que han existido en la literatura sobre trasplantes en el campo del Derecho, a través de los trabajos de los principales juristas que han estudiado esta materia.

\section{2. ¿Qué es un trasplante institucional?}

El término "trasplante legal" o "trasplante jurídico" fue acuñado por Alan Watson en su libro Legal transplants: An Approach to Comparative Law de 1974. Por eso, la definición comúnmente usada por el mundo académico es la de Watson (1974): "el traslado o transferencia de una regla o sistema legal de un país a otro o de un pueblo a otro". Aunque este autor pertenecía a la disciplina de Historia del Derecho, el estudio de los trasplantes institucionales ha sido competencia casi exclusiva de la disciplina de Derecho comparado, que es la rama del Derecho que intenta explicar los cambios jurídicos y la difusión del Derecho, comparando los diversos sistemas legales que existen. Según Rodolfo Sacco (1991, p. 388): "el Derecho comparado examina la forma en la que las instituciones legales se conectan, diversifican y trasplantan de un país a otro". También la rama denominada Derecho y Economía o Análisis Económico del Derecho ha analizado esta problemática desde el punto de vista de sus efectos económicos.

Los comparativistas han estudiado los trasplantes que se han producido en la historia, remontándose incluso al Código de Hammurabi del siglo XVII a.C. No es, por tanto, algo nuevo como plantea la NEI, sino que, a lo largo de la historia, los países se han prestado leyes, normas o prácticas. En el caso de las conquistas y el colonialismo, el trasplante fue impuesto por los gobernantes a los pueblos conquistados o colonizados. Pero en otras ocasiones, la adopción de una determinada norma o concepto jurídico ha sido buscada voluntariamente por el país receptor.

\section{Los trasplantes institucionales en la economía}

La literatura que estudia el impacto de las instituciones en el crecimiento económico sostenido es extensa. Ilustres representantes de la NEI, como el Premio Nobel Douglass North, han investigado este tema. Por eso, la NEI es una de las ramas de la economía que se ha planteado recientemente la utilidad de los trasplantes institucionales como medio para promover el desarrollo económico, aunque apenas existan trabajos que analicen concretamente la relación entre esas dos variables.

La posibilidad de que los trasplantes de instituciones exitosas promuevan el crecimiento del país receptor parte de la hipótesis, formulada por los neoinstitucionalistas, de que unas buenas instituciones generan crecimiento económico. Algunas de estas "buenas instituciones" serían por ejemplo las que limitan la acción del gobierno, evitan la corrupción, moderan los impuestos, protegen los derechos de propiedad o garantizan el cumplimiento de los contratos. La importancia de un "buen gobierno" es un argumento muy arraigado en la literatura sobre las causas del crecimiento económico.

La Porta, López de Silanes, Shleifer y Vishny (1999) nos indican que la calidad de los gobiernos varía mucho de un país a otro. Así mismo señalan que el desempeño gubernamental depende de las circunstancias históricas y del desarrollo económico de los países.

El economista turco Dani Rodrik $(1997 ; 2000)$ analiza la relación entre democracia y estabilidad económica y encuentra una relación estadísticamente significativa y cuantitativamente amplia entre estas dos variables. A pesar de que la mayoría de los estudios han tenido como resultado que la democracia no tiene ningún efecto sobre el crecimiento económico de un país, Rodrik demuestra empíricamente que los países con regímenes políticos más democráticos tienen mayor estabilidad macroeconómica. Las democracias son menos volátiles, manejan mejor los shocks adversos y también son mejores distribuyendo las rentas, por lo que se puede inferir 
que están dotadas de mejores instituciones que contribuyen al desarrollo de ese país. La volatilidad económica es una característica de los países subdesarrollados y el mayor obstáculo para su crecimiento. Por ello, la realización de ciertos cambios políticos, como la implantación de restricciones al ejecutivo, la garantía de un Estado de Derecho (rule of law) o la separación de poderes, es una buena estrategia para intentar conseguir un régimen más participativo que haga que la inestabilidad disminuya y que esa nación pueda crecer.

En el libro ¿Por qué fracasan los países? (2012), el profesor de Economía del MIT, Daron Acemoglu, y el profesor de Ciencias Políticas de Harvard, James A. Robinson, también intentan explicar qué hace falta para que un país crezca, llegando a la conclusión de que los factores que determinan la prosperidad de una nación no son los que tradicionalmente se han considerado como las razones de las desigualdades económicas entre los países, es decir, geografía, clima y cultura, sino la política económica que hagan sus líderes y sus instituciones. A esta misma conclusión llegan Rodrik y Subramanian (2003).

Acemoglu y Robinson (2012) diferencian entre instituciones inclusivas, más democráticas y progresistas, de libre mercado, que promueven el espíritu emprendedor y conllevan un mejor reparto de la riqueza, límites al poder de los gobernantes y unas mayores libertades; y extractivas, es decir, explotadoras, herméticas, absolutistas, dirigidas básicamente a exprimir a los ciudadanos y a perpetuar a las élites en el poder. Parece claro, por tanto, que los políticos de los países que quieran progresar necesitan importar instituciones inclusivas. Sin embargo, algunas naciones se quedan atrapadas con instituciones extractivas por los grandes beneficios que esto supone para las élites.

Estos autores nos dicen que si determinados países no crecen es por los obstáculos políticos, por las malas políticas públicas que generan malas instituciones. El ejemplo más claro de que sí se puede lograr el crecimiento es Botswana, el único país del África subsahariana que ha tenido un crecimiento alto y sostenido desde su independencia, y todo debido al desarrollo de un estado precolonial eficaz y centralizado con unas instituciones inclusivas. Este ejemplo nos demuestra que no hay algo intrínseco en África que les impide crecer, como alegan algunos autores. Para Acemoglu y Robinson, con un marco institucional adecuado que ponga límites al poder, garantice una justicia independiente y una separación de poderes e incentive la inversión y la apertura económica, cualquier país puede tener éxito económico.

Por su parte, Mancur Olson (1996) afirma que el desempeño económico depende de la estructura de incentivos que, precisamente, crean las instituciones. Olson insiste en que las diferencias de ingreso per cápita entre los países pobres y ricos se deben a la distinta calidad de sus instituciones.

William Easterly, profesor de Economía de la Universidad de Nueva York y ex empleado del Banco Mundial, también refuta las teorías tradicionales del desarrollo en su libro En Busca del Crecimiento (2003). Al igual que Olson, cree que los países menos desarrollados no consiguen crecer porque no existen los incentivos adecuados.

Todas estas investigaciones nos sugieren que una mejora en el marco institucional y en la forma de gobernar de ciertos países podría mejorar su desempeño económico. Por eso, a finales del siglo XX se utilizaron los trasplantes institucionales para cambiar economías planificadas a sistemas de libre mercado, fomentando así la inversión extranjera, que es uno de los principales motores del crecimiento económico de un país. En la década de los años 90 del siglo pasado proliferaron los proyectos de Derecho y desarrollo que utilizaban las reformas o trasplantes de instituciones como una herramienta para llevar la democracia y el crecimiento económico a los países más atrasados. En esa misma década, agencias internacionales como el Banco Mundial, a través del Banco Internacional para la Reconstrucción y el Desarrollo (BIRD), el Fondo Monetario Internacional o el Banco Europeo para la Reconstrucción y Desarrollo, destinaron grandes cantidades de dinero para intentar reformas legales en los países en transición, en especial en Europa del este y en países que acababan de salir de un conflicto, como Afganistán o Iraq (Twining, 2004, p. 30).

Sin embargo, como hemos dicho anteriormente, disponemos de muy pocos estudios relativos a la relación entre trasplantes institucionales y crecimiento económico. Los economistas Daniel Berkowitz y Jean-Françoise Richard y la jurista Katharina Pistor son de los pocos autores que 
han llevado a cabo estudios empíricos sobre el impacto de los trasplantes de normas en el desarrollo económico. Estos autores utilizan el término "legalidad" para referirse a la efectividad de las instituciones que hacen cumplir la ley y no a la calidad de las leyes contenidas en los códigos (Berkowitz, Pistor y Richard, 2003). En un primer artículo estudian la relación entre el desarrollo económico y esta legalidad usando datos de 49 países. Estos autores reconocen que los programas de asistencia legal, que asumen que proporcionar las leyes adecuadas mejorará la legalidad y en última instancia el crecimiento económico, en su mayoría no han producido los resultados esperados. Esto es debido, según estos autores, a que, para que las leyes sean efectivas, tienen que ser acordes al contexto en el cual se van a aplicar, de tal manera que los ciudadanos tengan incentivos para cumplirlas y para demandar instituciones que las ejecuten y desarrollen. Dicen que los intermediarios legales - políticos, jueces, abogados, etc.- son los responsables de mejorar la calidad de esas instituciones en respuesta a las demandas.

Estos autores consideran que la forma en que un sistema legal se trasplanta a otros países es un determinante de la legalidad y el desarrollo económico más importante que el suministro de un código de una determinada familia legal. Dicen que las tres familias legales más importantes, el Derecho común inglés, el Derecho civil francés y el Derecho civil alemán, han sido las más trasplantadas y, por lo tanto, son de las que derivan la mayoría de los sistemas legales. Algunos autores incluyen también el Derecho escandinavo como una cuarta familia. Estas familias legales son analizadas ampliamente por La Porta junto a López de Silanes, Shleifer y Vishny en "Law and Finance" (1998), artículo que parte de la afirmación de que, en la mayoría de países, las leyes (en este caso las leyes financieras que protegen al inversor) no se han creado de cero, sino que han sido trasplantadas de una de estas familias legales $\mathrm{y}$, por eso, han seguido diferentes caminos.

Berkowitz, Pistor y Richard (2003) utilizan la expresión "efecto trasplante" para referirse a lo que ocurre cuando la nueva ley no se adapta a las condiciones locales. En esta situación, los ciudadanos del país receptor no están familiarizados con la norma trasplantada y, por tanto, previsiblemente no la usarán en la práctica. Los intermediarios de los que hablamos anteriormente tendrán más dificultades a la hora de desarrollar la ley de acuerdo con la demanda y, por eso, el trasplante realizado será menos efectivo. Como podemos observar, hablar del "efecto trasplante" es lo mismo que hablar del path dependence o "dependencia de la trayectoria". Su análisis econométrico muestra que el "efecto trasplante" tiene un impacto indirecto en el desarrollo económico a través de su efecto directo negativo en la legalidad, es decir, en la efectividad de las instituciones.

Estos autores sostienen que, para que una reforma institucional sea efectiva, se deben escoger normas o instituciones cuyo significado pueda entenderse por las personas a las que van dirigidas, para que la puedan usar. Por eso sugieren dos alternativas: o bien que los préstamos se hagan entre países con una herencia legal parecida -aquí entran en juego las distintas familias legales-, o bien que se invierta en informar y preparar a la población antes de que la nueva ley sea adoptada. La familiaridad actúa como un factor que incrementa la receptividad del trasplante.

En un segundo artículo, dedicado enteramente al "efecto trasplante", estos autores hacen afirmaciones importantes, como que, a pesar de que se está produciendo en el mundo un fenómeno de convergencia de leyes, la manera en la que funcionan las instituciones y su efectividad difiere sustancialmente de un sistema a otro. Por eso, y tras un extenso análisis empírico, concluyen que una reforma legal solo producirá los efectos deseados si las leyes importadas se adaptan a las condiciones locales.

Se debe tener muy en cuenta el grandioso trabajo de estos tres autores, que consideran que la familiaridad, la comprensión, la adaptación y la demanda voluntaria de las normas son requisitos necesarios para que el trasplante funcione.

El economista Thrainn Eggertsson, otro de los pocos autores que ha estudiado el éxito o fracaso de los trasplantes en general, señala que, para ser eficaces, las nuevas tecnologías de producción deben apoyarse en lo que él llama "tecnologías sociales". Eggertsson (2005, p. 10) sostiene que: "la política institucional es el arte de impulsar la aparición de tecnologías sociales mediante la creación de nuevas instituciones o la reforma de las existentes". 
Este autor también afirma que una de las razones más nombradas del fracaso de los trasplantes de normas es la relativa al comportamiento de la élite política o el grupo que ostenta el poder en el país receptor. El problema radica en que los líderes estarían dispuestos a soportar un marco institucional que genera malos resultados económicos si ven ese trasplante como una amenaza para su permanencia en el poder. Para este autor, "la historia importa" y sirve para explicar, por ejemplo, el estancamiento económico de países como los del África subsahariana. Eggertsson cree que una transferencia de normas tendrá éxito si las autoridades del país importador "proveen la infraestructura y los recursos financieros necesarios para que el sistema legal funcione adecuadamente" (Eggertsson, 2005, p. 15). También reconoce la importancia del fenómeno del path dependence, al contemplar que las nuevas instituciones puedan entrar en conflicto con los intereses materiales y los valores de la sociedad receptora, dando lugar a un rechazo del trasplante. Coincide con Berkowitz, Pistor y Richard en que, para que la nueva norma tenga éxito, debe existir una demanda generalizada de la misma. Si no es así, los ciudadanos del país que importa esa norma no la cumplirán. Afirma que las reformas exitosas serán las que sean selectivas y flexibles, permitiendo por tanto realizar ajustes, y las que se apoyen en medidas que puedan sortear los obstáculos sociales y políticos que puedan surgir.

Queremos destacar la importante aportación de este autor que, entre otras cosas, expone el que es, a nuestro juicio, el mayor obstáculo para los trasplantes: una élite gobernante a la que beneficien unas malas instituciones.

\section{Los trasplantes institucionales en el campo del derecho}

Como hemos adelantado anteriormente, hay dos posturas básicas en la literatura jurídica relativa a los trasplantes institucionales. Por un lado están los defensores de este tipo de reforma legal, a los que Margit Cohn llamará "transferistas", como Alan Watson o William Ewald. Y, por el otro, los autores más escépticos que, o bien creen que el trasplante es imposible, como en el caso de Pierre Legrand, o bien piensan que es difícil que estos préstamos de leyes sean exitosos porque la ley es básicamente una creación social y, por lo tanto, está vinculada a un contexto socioeconómico determinado. Este último es el caso de Otto Kahn-Freund, Esin Örücü o Thrainn Eggertsson, a quienes, según la terminología usada por Cohn, que es la más extendida en la literatura, se les denominaría "culturalistas".

Antes de extendernos en los trabajos de los autores contemporáneos, debemos recordar a Montesquieu, quien ya en el siglo XVIII trataba este tema en su libro Esprit de Lois con su famosa frase: "las leyes políticas y civiles de cada nación deberían estar tan hechas a medida de las personas para las que son elaboradas que sería pura casualidad si las leyes de una nación pudieran satisfacer las necesidades de otra" (Montesquieu, 1758). Por lo tanto, para Montesquieu, sólo en casos excepcionales las instituciones de un país pueden ser válidas para otro. Para este pensador francés, las leyes están estrechamente unidas a su entorno. En su opinión, el "espíritu de las leyes" está conformado por un grupo de factores, entre los que se encuentran: el clima, la religión, las leyes, las costumbres, las tradiciones o las máximas del gobierno. No cabe duda, por tanto, de que Montesquieu era "culturalista".

Como ya hemos adelantado, el mayor defensor de los trasplantes es Alan Watson. Sus trabajos se centran en la historia del Derecho occidental y, más concretamente, en el Derecho romano. Su tesis principal es que los trasplantes han sido el instrumento más importante para la construcción y transformación del Derecho en el mundo. Esta teoría fue muy innovadora porque iba en contra de un supuesto generalmente aceptado por el pensamiento jurídico: que la ley cambia en respuesta a fuerzas externas a ella y que, tal y como dice la llamada "teoría del espejo", la ley no es autónoma sino que refleja las relaciones de la sociedad, el funcionamiento del mercado o la ideología política. Para los defensores de esta "teoría del espejo", como Savigny, Hegel o Marx, la economía y la sociedad, entre otros factores, moldean la ley (Ewald, 1995). Para Watson, sin embargo, la ley está aislada y no depende del cambio social, político o económico. Este jurista cree que las instituciones pueden ser transportadas fácilmente de una sociedad a otra y, para demostrarlo, proporciona numerosos ejemplos de trasplantes históricos exitosos de normas e incluso de sistemas jurídicos enteros, como el trasplante del Derecho romano a numerosos países del continente europeo. Lo que no especifica es qué criterio sigue para denominar 
"exitoso" a un trasplante. La exportación e importación de normas es posible por la autonomía del Derecho frente a los contextos sociales que regula. Watson nos explica que las normas de Derecho romano fueron trasplantadas en bloque a la mayoría de países de Europa debido a su gran prestigio. Sin embargo, dice que para saber si es conveniente el trasplante se debe hacer un análisis de cada caso.

Esta última proposición choca con el tono general de su libro, en el que defiende tan a ultranza los trasplantes y el aislamiento de las normas, que no contempla la posibilidad de que alguno pueda fracasar por estar una ley demasiado ligada a la sociedad en la que se ha dictado. Nadie puede negar que el Derecho romano se trasplantase, pero no por eso todo el Derecho es trasplantable.

William Ewald se presenta como un seguidor del trabajo de Watson. Cree que su teoría del cambio jurídico se ha malinterpretado y su objetivo es intentar clarificarla. Señala que la interpretación errónea de las palabras de Watson es debida a que se ha prestado poca atención a la estructura lógica de su argumento. Este autor, representante de la disciplina de Filosofía del Derecho, acuña el término "Jurisprudencia comparada" para referirse al nuevo estilo de análisis del Derecho comparado que se crea tras las aportaciones de Watson.

Ewald (1995) cree que en la argumentación de Watson conviven dos teorías, a las que apoda "Watson fuerte" y "Watson débil", porque una es más agresiva y más extrema, y por eso ha de ser descartada, mientras que la otra es más cautelosa y flexible y es con la que debemos quedarnos. Aclara que Watson no descarta que haya relación entre Derecho y sociedad sino que dice que es una relación tan compleja que debe ser estudiada caso por caso. Además, las investigaciones de Watson se centran casi exclusivamente en el Derecho privado de Europa occidental con lo que sus conclusiones no pueden ser extrapoladas a la ley en general. Para Ewald, Watson consigue destruir la teoría tradicional del espejo pero no proporciona su propia teoría sobre el Derecho y la sociedad. Por eso, se deben seguir haciendo estudios e investigaciones para conseguir llegar a conclusiones generales válidas.

Creemos que este autor consigue aquí dos cosas muy importantes: moderar el discurso de Watson y explicar sus ideas de una manera más eficaz. Así mismo, propone la realización de más y mejores estudios, algo que consideramos crucial para una mayor comprensión del funcionamiento de este fenómeno y su aprovechamiento para fines económicos.

Como ya habíamos apuntado, Pierre Legrand se erigió como el mayor crítico de las teorías de Watson y los "transferistas". En su complicado artículo, "The Impossibility of Legal Transplants", se mofa de los argumentos de Watson y expone una teoría un tanto débil que acaba con dos afirmaciones que pueden parecer incompatibles: que es imposible trasplantar las normas; y que, debido al nexo entre las normas y la cultura en que se aplican e interpretan, lo que se trasplanta es sólo el texto de la norma, no su significado. Está totalmente en desacuerdo con la visión de Watson que considera que las normas están aisladas de la sociedad. Legrand cree que sí están íntimamente ligadas a la sociedad en la que nacen y no pueden ser separadas de ella, por lo que es imposible que viajen de un ordenamiento jurídico a otro. Señala que para que se dé un trasplante que tenga sentido, la regla completa, entendida como la suma de su texto y su significado, debe ser trasladada de una cultura a otra y, dado que el significado de la regla está ligado a una cultura específica, le es difícil concebir que esto pueda pasar. Dice que cuando una norma se importa, adquiere un significado local que hace que la propia regla cambie y, como el significado no es trasplantable, la norma tampoco lo es. Legrand (1997) tacha de "simplista, superficial y engañosa" la postura de Watson y sus seguidores. Para este autor, el Derecho no debe ser separado de los contextos en los que surge ya que son los que dan sentido y legitimidad a las normas.

Legrand peca, al igual que Watson, de demasiado radical en sus postulados. Entre el todo y la nada, el siempre y el nunca, hay un punto intermedio. Se acercaría más a la realidad si dijera que algunas leyes son difícilmente separables de los contextos en los que se aplican y, por tanto, al trasplantarlas no surtirán el efecto deseado, mientras que otras sí son susceptibles de ser trasplantadas con éxito.

Así las cosas, no es raro que Watson contestara a estos ataques en otro famoso artículo, más flexible y realista, en el que intenta aclarar los argumentos esgrimidos en su libro de 1974. Aquí Watson ridiculiza las ideas de su crítico más feroz diciendo, entre otras cosas, que sus palabras 
parecen importantes pero carecen de sustancia. Y tiene razón, porque el artículo de Legrand utiliza palabras muy cultas y un lenguaje tremendamente enrevesado para luego no decir prácticamente nada. Watson (2000) dice estar de acuerdo con Legrand en que la norma, una vez trasplantada, pasa a ser distinta de la que era en su país de origen. Esta idea será compartida por la mayoría de los autores. De hecho, la jurista Esin Örücü (2000) señala que, aún en el caso de trasplantes exitosos, las instituciones sufren una contaminación debida al nuevo entorno y, por lo tanto, pasan a ser instituciones o conceptos distintos.

Watson alega que su mayor queja en relación a Legrand es que éste niega la historia del Derecho comparado, porque si algo ya se ha hecho es porque se puede hacer. Este es el hecho más indiscutible que pone de manifiesto. Así mismo, este autor cree que los trasplantes institucionales son inevitables y que están tan vivos como en los tiempos de Hammurabi (Watson, 2000). En este artículo, Watson aboga por la idea de un solo Código de Derecho civil para toda la Unión Europea. Legrand, como era de esperar, se manifiesta abiertamente en contra de esta idea.

Otto Kahn-Freund es otro "culturalista" detractor de los trabajos de Watson y compañía. Sin embargo, aunque su diferenciación entre uso y abuso del Derecho comparado pueda aparentar lo contrario, no es tan extremista como Legrand. Kahn-Freund (1974) cree que es lógico que los encargados de elaborar las leyes busquen ideas en el exterior con uno de los siguientes propósitos: para preparar una unificación internacional del Derecho, como en el caso de la entrada de un país en la Unión Europea; para dotar de eficacia legal a un cambio social que ya ha ocurrido, por ejemplo la reforma de la ley del divorcio; o para promover un cambio social en el país receptor, por ejemplo la supresión de la discriminación racial. Kahn-Freund nos habla de dos tipos de trasplantes, el orgánico (de un riñón), que es difícil y puede acabar con el rechazo del órgano; y el mecánico (de un carburador), que es relativamente fácil. Señala que los trasplantes jurídicos no pertenecen a ninguno de estos dos tipos ya que el grado en el que una norma pueda ser transferida dependerá de cada caso en cuestión. Kahn-Freund cita a Montesquieu para exponer a continuación su tesis principal: que, con el tiempo, los elementos geográficos, económicos, sociales y culturales de la tesis de Montesquieu han perdido importancia, mientras que los factores políticos han ganado notoriedad. Dice que los países desarrollados -y las clases dominantes de los países en vías de desarrollo- han sufrido un proceso de integración económica, social y cultural pero de diferenciación política (Kahn-Freund, 1974). Esto significa que los obstáculos para el trasplante relativos al entorno se han reducido, en gran medida debido al desarrollo de las comunicaciones y, en los últimos tiempos, a la globalización, que hace que las ideas jurídicas se muevan libremente por el mundo. Sin embargo, Kahn-Freund asegura que sí persiste, y de forma más intensa que en los tiempos de Montesquieu, el obstáculo político, que se traduce en que las diferencias entre los sistemas políticos del mundo pueden ser un impedimento para el éxito de los trasplantes institucionales. Lógicamente tenemos que analizar las palabras de KahnFreund con máxima cautela puesto que las escribió en 1974. Hoy, en 2016, el panorama internacional ha cambiado mucho.

Por tanto, para este autor, las instituciones son trasplantables, aunque siempre existe el riesgo de rechazo. Por eso, los legisladores deben conocer no solo la ley extranjera, sino también su contexto social y político. El grado en que las instituciones puedan ser trasplantadas dependerá de su mayor o menor vinculación con la sociedad de esa nación, es decir, habrá que ver hasta qué punto ese país depende del camino que han ido creando las tradiciones, creencias y valores (instituciones informales) de su sociedad. Esto es, como hemos visto, lo que se conoce como path dependence o "dependencia de la trayectoria". Para este autor, ignorar el contexto constituye un abuso del Derecho comparado.

Pensamos que Kahn-Freund está bastante acertado en la mayoría de sus afirmaciones. Habla de grados de trasplante y de riesgo de rechazo, que son, creemos, dos de las claves para el estudio de este fenómeno. Lo que no nos convence es su tesis de la diferenciación política que, como hemos apuntado antes, ha quedado obsoleta.

Los autores Virginie Mamadouh, Martin De Jong y Konstantinos Lalenis también estudian el problema del path dependence, que para ellos se traduce en que las normas o instituciones están tan ligadas al contexto socioeconómico del país dónde se originaron que al viajar a otro contex- 
to distinto pueden producir problemas de adaptación e incompatibilidades (Mamadouh, De Jong y Lalenis, 2003). Estos autores reconocen que la transición hacia las nuevas instituciones es difícil y a veces puede resultar incluso traumática. También los economistas Dani Rodrik y Arvind Subramanian (2003, p. 33) nos advierten de que: "las soluciones institucionales que sirven en determinado ámbito pueden ser inapropiadas en otro que carezca de las normas y las instituciones complementarias. En otras palabras, las innovaciones institucionales no siempre se trasplantan bien".

A pesar de este temido obstáculo al que llamamos path dependence, sabemos que cambiar la cultura social o las creencias y tradiciones locales no es imposible. Ciertos trasplantes de normas o prácticas han logrado superarlo y tener un cierto éxito, aunque de forma muy concreta y localizada. Este es el caso, por ejemplo, de los microcréditos concedidos a mujeres de Bangladesh, que consiguieron reducir la pobreza y le valieron a su creador, Muhammad Yunus, el Premio Nobel de la Paz en 2006, aunque con posterioridad su eficacia haya sido muy cuestionada por algunos economistas.

Gunther Teubner es un teórico del Derecho y la sociología que opina, al igual que KahnFreund, que las instituciones no pueden ser trasladadas fácilmente de un contexto a otro, sino que necesitan ser implantadas y cultivadas en el nuevo entorno. Hablar de Gunther Teubner es hablar irremediablemente de su metáfora de los "Legal Irritants". Este autor utiliza este término para referirse a los préstamos de instituciones, que él considera más irritaciones -o molestiasque trasplantes (Teubner, 1998). Analizando el principio de buena fe, que fue trasplantado al Derecho contractual británico -y por tanto al Derecho común- en 1994 proveniente de los países de la Unión con Derecho civil, Teubner tacha de engañosa la metáfora del trasplante. La razón es que esa palabra, "trasplante", hace parecer que la norma trasplantada se quedará igual, y que sólo hay dos resultados posibles: el rechazo o la integración. Sin embargo, Teubner cree que esto no es para nada así, sino que se trata de una irritación que desencadena una serie de eventos nuevos e inesperados. Tanto el significado como el contexto interno de la norma trasplantada experimentarán un cambio fundamental para adaptarse al nuevo entorno cultural. Teubner se opone a dos de las teorías más importantes del Derecho comparado: la de la convergencia y la de la equivalencia funcional. La primera considera que, debido a fenómenos como la globalización, los países tienden a converger hacia estructuras socioeconómicas similares. Esto llevaría consigo también la uniformidad de leyes. La segunda también implica una tendencia hacia la convergencia, dado que las soluciones que se dan en distintos sistemas para los mismos problemas son contempladas como equivalentes. Pues bien, Teubner considera que estos fenómenos, en vez de producir leyes uniformes, contribuyen a la fragmentación de las normas y a la divergencia entre los sistemas. De hecho, pone de manifiesto que, a pesar de que se pensara que la globalización llevaría a una convergencia de los distintos regímenes económicos del mundo, ha ocurrido lo contrario. Aunque este autor reconoce una cierta autonomía de las normas, nos avisa de las consecuencias de arrancar una regla de sus raíces nacionales. Está en contra de reducir el debate de los trasplantes a una mera lucha "contexto versus autonomía". Él prefiere utilizar un término intermedio, "arreglos legales vinculantes", para describir la situación en la que el nexo entre Derecho y sociedad es selectivo y sólo existe conexión con determinados fragmentos de la sociedad (Teubner, 1998, p. 17).

Creemos que este autor no tiene una base real para desmontar las tesis comparativistas de convergencia y equivalencia funcional, que, a nuestro juicio, explican con claridad lo que ocurre realmente en el mundo. Por otro lado, su afirmación de que la norma trasplantada sufrirá enormes cambios en la sociedad receptora no es una aportación innovadora puesto que, como hemos visto, ya habían llegado a la misma conclusión tanto Watson como Legrand.

Teubner también aborda el problema del path dependence y coincide con Kahn-Freund en que algunas instituciones están tan entrelazadas con la cultura política, económica, científica o tecnológica de una sociedad que su transferencia a otra distinta requiere profundos cambios en el nuevo sistema político.

William Twining también escribió ampliamente a principios del siglo XXI sobre la difusión del Derecho en relación a los trasplantes institucionales. Este autor engloba los trasplantes de normas dentro del término "difusión" y destaca su conexión con otras ciencias sociales, como la sociología, la antropología o la economía. A diferencia de Watson, cree que el aislamiento de 
normas es excepcional, y prueba de ello es la continua interacción entre los distintos sistemas legales que existen. Explica que los estudios sobre trasplantes son extensos y variados y se remontan a los escritos de Gabriel Tarde, Sir Henry Maine o Max Weber (Twining, 2004, p. 8). Pone como ejemplos la recepción del Derecho romano en la Europa medieval, la imposición de normas por los colonizadores o la importación voluntaria de códigos en Turquía o América Latina.

Twining (2004) distingue tres procesos de difusión del Derecho: el instrumentalista, el contextual o expresivo y el ideológico. En este último tipo se considera que las reglas y disposiciones están enraizadas con los valores, las creencias, los principios y los intereses políticos de la sociedad. Según esta visión, el Derecho es resultado de esos valores y tradiciones y por tanto refleja esa sociedad o cultura (teoría del espejo).

Este autor analiza el modelo estándar de trasplantes, cuyas características principales son (Twining, 2004, p. 3):

- un único importador y un único exportador.

- la transferencia de normas se realiza entre países.

- se trata de una transmisión de una sola vía o unidireccional.

- el objeto trasplantado suele ser una regla o un concepto.

- los agentes principales del trasplante son los gobiernos.

- la recepción se realiza con una promulgación formal o adoptando la norma en un momento concreto.

- el objeto (la norma o el concepto) mantiene su identidad sin que tenga lugar un cambio significativo en el mismo.

- normalmente se traslada una norma de un sistema más desarrollado a otro dependiente o menos desarrollado.

- la norma recibida llena un vacío o reemplaza una norma anterior que se había quedado obsoleta.

Pues bien, Twining cree que este modelo simplista está desfasado y que sus generalizaciones son, entre otras cosas, superficiales, engañosas y, en ocasiones, directamente falsas. Este modelo quizá era adecuado para los ejemplos históricos de transferencias de normas, pero en el mundo complejo del siglo XXI no podemos seguir basando los estudios en esos supuestos. Señala Twining que actualmente los sistemas legales que coexisten tienden a la convergencia ya que se influencian entre sí, complementándose, imitándose, cooperando e incluso fusionándose. Por esta razón, construye una tabla con algunas variantes al modelo estándar (Twining, 2004, p. 17). No es nuestra intención enumerar aquí todas las categorías de trasplantes que contempla, pero sí mencionaremos lo que Twining considera más importante, es decir, cómo cambian los supuestos del modelo estándar al considerar uno más complejo (Twining, 2004, p. 18):

- no siempre hay sólo un importador y un exportador. A menudo las fuentes de importación son diversas, como en el caso de Turquía que importó ideas de varios países europeos.

- la difusión puede tener lugar entre muchas clases de sistemas y en distintos niveles, no sólo de forma horizontal y a nivel estatal.

- la transmisión no tiene por qué ser directa y unidireccional, también hay difusión indirecta e influencias recíprocas.

- los trasplantes no siempre requieren una adopción formal de la disposición importada, existe también la llamada "interacción informal", en la que se recibe una determinada norma a través de una decisión judicial o ejecutiva. También es lo que ocurría cuando una idea era transportada de un sitio a otro por colonizadores, misioneros o mercaderes.

- el objeto del trasplante no es únicamente una norma o concepto legal, también pueden trasplantarse procedimientos, estructuras, métodos, prácticas, costumbres e incluso principios.

- los agentes no son necesariamente gobiernos, también juegan un papel importante a la hora de importar o exportar Derecho las élites, los comerciantes, los misioneros, los fieles de una determinada religión, los inmigrantes, etc.

- no suele haber una fecha oficial de recepción de la norma importada, normalmente los trasplantes son procesos largos y graduales. 
- no siempre se trasladan las disposiciones de una nación desarrollada a un país con un sistema menos desarrollado.

- la norma trasplantada normalmente no mantiene la misma identidad o forma que tenía en el país donante, sino que es objeto de cambios para adaptarla a las condiciones de la nueva sociedad en la que debe ser efectiva.

- la regla que se importa raramente llena un vacío o reemplaza enteramente una norma local. Lo normal es que haya un orden preexistente ya sea formal o informal.

Es indudable que el trabajo de Twining es muy útil para poder seguir estudiando el fenómeno de los trasplantes en el siglo XXI.

Siguiendo esta línea de pensamiento, la jurista Margit Cohn nos presenta una serie de tipologías de trasplantes. Esta autora argumenta que, a pesar de la abundante literatura que ha abordado este tema, no se ha prestado suficiente atención a la transformación del fenómeno. Los trasplantes ya no son eventos singulares sino que, al ser la realidad de hoy más compleja, se han convertido en una serie de eventos en los que multitud de agentes interaccionan entre sí (Cohn, 2010). Coincide con Twining en que la literatura se ha ido desarrollando en torno a un modelo simplista de trasplante que ya está pasado de moda, por lo que cree que es necesario reconsiderar los supuestos de ese modelo para crear uno más complejo acorde al nuevo contexto global. En este sentido, Mamadouh, De Jong y Lalenis (2003), a los que nos hemos referido anteriormente, apuntan que las nuevas tecnologías de la comunicación han aumentado considerablemente la velocidad a la que se intercambia la información, lo que facilita el conocimiento por todos los países de las instituciones y prácticas extranjeras. Además, la globalización hace que los países necesiten mejorar sus instituciones de cara a competir en el mercado mundial, por eso es cada vez más frecuente la importación de normas, prácticas o conceptos. El ejemplo más claro que utilizan es el de Al Jazeera, canal de televisión conocido como la CNN del mundo árabe porque copia las convenciones de la libertad de prensa (los procedimientos, formatos, valores, etc.) del periodismo anglosajón.

Las dos principales tipologías de trasplantes de Cohn (2010) son:

- los tipos de trasplante en base a los mecanismos o formas de adopción, ordenados por el grado de soberanía de facto, que son: la imposición, como en la colonización; el compromiso transnacional, como en el caso de normas de la Unión Europea que tienen efecto directo en los tribunales nacionales; la presión externa, que se da por ejemplo en el caso de condiciones impuestas por las Instituciones Financieras Internacionales a los países que quieran recibir sus préstamos; la generación de prestigio; y la adopción voluntaria. A estos tipos Cohn añade: la "fertilización negativa", en la que la norma es rechazada; y la innovación.

- los tipos en base al resultado del trasplante o a su grado de conformidad con la norma original, que son: la convergencia total, si funciona igual en el país receptor que en el de origen; lo que llama fine-tuning, cuando la alteración de la norma es mínima; la trasposición; la adaptación; la "fertilización cruzada", que ocurre cuando un estímulo externo promueve una evolución dentro del sistema legal receptor; la transformación sustantiva, para ajustar la norma al contexto; la distorsión; la mutación, con la que la norma pierde toda su semejanza con la original pareciéndose sólo en el texto; y el rechazo total.

Otros tipos de trasplante que contempla Cohn son los relativos:

- al tipo de influencia, que serían: el formal o directo y el informal o indirecto, como la fertilización cruzada;

- al tipo de exportador, que puede ser: un colonizador, un actor transnacional, una nación, un estado o una cultura no estatal;

- a la actitud de la sociedad receptora hacia el mismo, contemplando: la convergencia, el compromiso, la reticencia o la resistencia;

- al tipo de norma adoptada, como por ejemplo: el Derecho estatutario, la jurisprudencia o las prácticas; $\mathrm{y}$

- a las motivaciones del importador, entre las que se encuentran: la optimización, la armonización, el dictado externo, los motivos empresariales o de legitimación y prestigio, entre otros.

Como ya hemos apuntado, lo que pretende Cohn con sus clasificaciones es que se aborde el fenómeno del trasplante prestando una mayor atención a su complejidad. La ley es una creación social que evoluciona y el trasplante es una realidad más compleja de lo que se ha venido consi- 
derando. Es muy común que entre los sistemas legales afectados exista una interdependencia o una interacción recíproca. Pues bien, creemos que su trabajo es clarificador y constituye una importante aportación al estudio de los trasplantes institucionales.

El caso de Mathias M. Siems es muy curioso ya que estudia los trasplantes cuyo resultado es que la norma funciona mejor en el país receptor que en el de origen, a los que denomina "Overfitting Legal Transplants" (Siems, 2014). Siems toma prestado este término, overfitting, que se usa en estadística cuando un modelo tiene más variables explicativas de las necesarias, para describir los casos en los que ciertos factores hacen que una norma funcione mejor en el país que la recibe que en aquel en el que se originó. En la literatura se había hablado de los trasplantes en los que la norma funciona casi igual de bien en ambos países, de los que son irrelevantes y de los que son perjudiciales para el país receptor, pero hasta el trabajo de Siems ningún autor se había planteado la posibilidad de que una norma importada funcionara mejor en el país en el que se trasplanta que en el país que la vio nacer. Su razonamiento es que, igual que ciertas ideas o inventos tienen más éxito en otros países que en el país en el que se originaron, los conceptos jurídicos también pueden correr la misma suerte. Pone el ejemplo de las tarjetas de negocios, originadas principalmente en Inglaterra y Francia, pero mucho más exitosas en Japón. Este autor es un gran defensor de los trasplantes, ya que piensa que, si las condiciones son favorables, trasplantar instituciones, ya sea de forma voluntaria o involuntaria, puede funcionar mejor que crear una norma de cero.

Siems (2014) contempla cinco casos en los que se puede hablar de "overfitting transplants": - cuando el objetivo buscado por el trasplante es perseguido de forma más efectiva en el país receptor que en el de origen debido a las condiciones culturales, políticas o socioeconómicas más favorables del primero;

- cuando la mezcla de la ley antigua y la nueva crea un beneficio mayor en el país importador que en el país de origen;

- cuando en el país receptor la institución trasplantada cumple una función adicional como por ejemplo la de generar legitimidad o la de ser beneficiosa económicamente;

- cuando la institución es más duradera en el país importador que en el exportador, y

- en el caso de ideas legales que no se han llevado a cabo en los países en que se originaron pero sí en otros países.

Aunque, a priori, resulte difícil creer en la tesis de Siems, la verdad es que su artículo es bastante convincente. Además, su original visión debería hacer que confiáramos más en la utilidad de los trasplantes para producir beneficios en el país receptor.

Además, este autor opina que la competición entre sistemas legales es una buena herramienta para identificar cuáles son las mejores instituciones para que los demás países puedan tomarlas prestadas.

Otro autor que también cree en la competencia entre ordenamientos jurídicos para lograr la ley más eficiente es Ugo Mattei. Este comparativista abre un nuevo campo al utilizar las herramientas del Derecho comparado y del Análisis Económico del Derecho para evaluar los trasplantes institucionales desde el punto de vista de la eficiencia económica. Mattei trata de averiguar qué trasplantes son apropiados dadas unas determinadas circunstancias y cómo pueden ser llevados a cabo. Para los "transferistas", encabezados por Alan Watson, la motivación más común para tomar prestada una determinada norma es su prestigio, que hace que suela ser trasplantada de un sistema más desarrollado a otro menos desarrollado - es lo que ocurrió con el Código Civil francés, que fue copiado en numerosos sistemas de Derecho civil-. Los representantes de la disciplina de Law and Economics han criticado duramente los argumentos de Watson y compañía, porque tienen un enfoque distinto basado en la tendencia a adoptar la regla más eficiente, bien por elección voluntaria o por necesidad social. Tras un pequeño análisis económico, Mattei (1994) concluye que la convergencia de los sistemas legales -adopción de soluciones similares para problemas análogos- puede explicarse como un paso hacia la eficiencia y pone como ejemplo la ley de expropiaciones en la que, a pesar de las diferencias en el contexto institucional de los distintos sistemas, los principios subyacentes son muy parecidos. Este autor define la eficiencia como: "aquello que evita que se malgasten recursos, lo que hace que un sistema legal funcione mejor reduciendo los costes de transacción, aquello que es considerado 
mejor por los consumidores" (Mattei, 1994, p. 11). Mattei argumenta que la estructura de las normas puede explicarse como el resultado de un proceso competitivo y por lo tanto los trasplantes también. Cada doctrina utilizada en un sistema legal para resolver un determinado problema forma parte de un "mercado de cultura legal", que funciona como cualquier otro mercado (Mattei, 1994, p. 3). La competencia determinará la supervivencia de la doctrina más eficiente. Mattei utiliza el ejemplo del "trust" para ilustrar un caso en el que la competencia ha dado lugar a un trasplante. Este autor aboga, por tanto, por comparar las distintas alternativas y elegir siempre la solución más eficiente, aunque reconoce que, en determinadas áreas del Derecho, las tradiciones legales son tan fuertes que han desarrollado barreras contra los trasplantes. Se trata de nuevo del problema del path dependence.

Es innegable que los postulados de Mattei son de suma importancia. Creemos que encontrar la ley más eficiente es vital para conseguir que esa ley pueda ser trasplantada satisfactoriamente a otros países, ya que aumenta considerablemente las probabilidades de éxito. Nuestro razonamiento es que la norma más eficiente siempre podrá conseguir mejores resultados que otra que lo es menos, ya que su aplicación en el país receptor y su cumplimiento por parte de la sociedad a la que va dirigida sería una estrategia óptima para todos los implicados.

También la profesora universitaria Esin Örüiü, a la que nos hemos referido antes, habla de la nueva tendencia del Derecho comparado relativa a la economía, en la que los economistas pretenden que los distintos sistemas legales compitan entre sí para poder dar con las mejores y más eficientes soluciones a los problemas legales que se plantean. Soluciones contenidas en normas que pueden después tomar prestadas todos los demás países.

Örücü (2000) propone sustituir el Derecho comparado tradicional o convencional por un enfoque denominado "Critical Comparative Law" que, entre otras cosas, aborda los problemas de incompatibilidades en los trasplantes. Cree que la interacción más importante entre países es la que ocurre en el seno de la Unión Europea, que persigue, en última instancia, la armonización aunque la autora prefiere utilizar el término "armonía"- e integración de normas dentro de la diversidad. Esta autora utiliza el ejemplo de Turquía para ilustrar algunos de sus argumentos, ya que el sistema legal de este país es fruto de un fenómeno único de traslado de leyes. Tanto su Derecho público como su Derecho privado son el resultado de trasplantes e influencias de varios modelos occidentales, sobre todo, de códigos del continente europeo de los que se eligieron y trasplantaron las mejores leyes de cada campo.

Örücü cree que los trasplantes actuales no pueden calificarse de voluntarios porque, en la mayoría de los casos, se les da a los países un determinado periodo de tiempo para adoptar una determinada institución y porque los agentes exportadores son los que manejan toda la situación. Este es el caso de los países que desean unirse a la Unión Europea, por ejemplo. En este sentido, Mamadouh, De Jong y Lalenis (2003) apuntan que, aún hoy, existen trasplantes realizados por coerción, como los que fuerzan a realizar agencias internacionales, como el Banco Mundial y el FMI, para conceder sus préstamos. Para ellos, los trasplantes que forman parte de las condiciones impuestas por estos organismos para la concesión de ayudas son involuntarios, y los asimilan a los impuestos por los colonizadores en las colonias.

Para Örücü, las incompatibilidades en los trasplantes llevan en la mayoría de los casos a la creación de sistemas mixtos en los que la cultura legal coexiste con la social. El grado en el cual ambas se mezclen dependerá de diversos factores. Sus famosas metáforas culinarias, "mixing bowl", "salad bowl", "salad plate" and "purée" nos muestran los distintos tipos de mezclas posibles (Örücü, 2000). Por último, también señala que, aún en casos de diferencias aparentemente irreconciliables, los comparativistas pueden construir un puente entre las culturas tradicionales y las normas o estándares que se pretenden trasplantar.

El trabajo de esta jurista es muy interesante. Su aportación más innovadora es poner de manifiesto que aún hoy existen trasplantes involuntarios, puesto que es un tema que, sobre todo en lo referente a la política de condicionalidad de las Instituciones Financieras Internacionales, requiere un examen más pormenorizado. Haría falta saber si un trasplante que un país no realiza voluntariamente puede funcionar alguna vez. Aunque, si ya es todo un reto que funcione uno buscado por el propio país receptor, que uno involuntario lo consiga es harto complicado.

Aunque, como vemos, existe una literatura bastante extensa en relación al análisis de los trasplantes legales, autores como Jonathan M. Miller han señalado que en esta abundante litera- 
tura teórica falta una clasificación que permita entender mejor este fenómeno. Por eso Miller divide los trasplantes en cuatro tipos en base a sus motivaciones. Muchos trasplantes mezclan varios de estos tipos. La aportación más importante del trabajo de clasificación de Miller es que, según él, el tipo de trasplante predice el camino que éste va a seguir (Miller, 2003). Vamos a ver los cuatro tipos de trasplante y su curso probable:

- el trasplante que ahorra costes. Ante un nuevo problema, el legislador del país receptor ahorra tiempo y dinero si toma prestada una solución que funciona en otro sistema legal en vez de crear una original. Este tipo está indicado sobre todo si, desde un punto de vista funcional, se cree que la nueva norma se puede adaptar bien al nuevo sistema. Sin embargo, este trasplante no se llevará a cabo si deja de ser aconsejable desde el punto de vista de la eficiencia económica.

- el trasplante determinado desde el exterior. Se produce, como ya hemos visto, cuando las instituciones financieras internacionales ponen como condición para formar parte de sus programas de desarrollo que el país del que se trate implemente determinadas reformas legales. También es el caso de gobiernos extranjeros que condicionan la realización de negocios con otros países a la adopción por parte de éstos de unas medidas principalmente aperturistas. El ejemplo más claro es la adopción de la legislación sobre derechos humanos por parte de países que desean evitar sanciones o beneficiarse de acuerdos comerciales. Este tipo de trasplante se llevará a cabo aunque sea ineficiente siempre que la presión externa y los incentivos compensen de algún modo esta ineficiencia. Sin embargo, fracasará cuando esa presión o esos incentivos desaparezcan, a no ser que la nueva norma haya calado muy hondo en el sistema receptor. Miller nos advierte de que en este tipo de trasplante se debe tener en cuenta tanto la motivación del donante como la del receptor ya que "el grado de presión externa afectará a la aceptación del trasplante" (Miller, 2003). Además, en este caso, es normal que el país importador realice un análisis costebeneficio para determinar si debería cumplir las condiciones impuestas por los organismos extranjeros o no.

- el trasplante entrepreneur o emprendedor. Tiene lugar cuando un grupo de individuos están dispuestos a invertir en la adopción de una norma extranjera ante la posibilidad de conseguir un beneficio. Este tipo de trasplante fracasará cuando la inversión del emprendedor se vuelva improductiva.

- el trasplante que genera legitimidad. Es el más frecuente. El prestigio de una determinada norma o sistema legal puede derivar de su eficiencia económica, como afirma Mattei, o de la autoridad legal de la que dota al sistema receptor, como apunta Watson. Este trasplante puede fallar si el país de origen o la propia norma o sistema legal pierden ese prestigio.

El trabajo predictivo de Miller es una buena herramienta a tener en cuenta cuando los países o las organizaciones internacionales pretendan realizar el trasplante de una determinada norma $o$ práctica en aras a intentar evitar su posible fracaso.

Mamadouh, De Jong y Lalenis también estudian los motivos de los trasplantes institucionales, que son de diversa índole, pero que siempre tienden a llevar mejoras a la sociedad receptora. Por eso se suelen transferir instituciones percibidas como exitosas. Otro motivo del que hablan varios autores es que los líderes de un determinado país quieran acabar con la resistencia a determinadas políticas progresistas. Los trasplantes también pueden ser utilizados como medio para acelerar el desarrollo económico de un país o para conseguirlo a un menor coste, que es precisamente la razón por la que comienzan a ser de gran interés para los economistas.

\section{Conclusiones}

Queda claro que los trasplantes de normas, doctrinas, prácticas o instituciones existen y no son imposibles como argumentaba Pierre Legrand. Existen porque hay numerosos ejemplos de transferencias de leyes e incluso de sistemas legales enteros, como ponen de manifiesto comparativistas e historiadores del Derecho, como Alan Watson. Además, este fenómeno no es algo novedoso, como parece deducirse del reciente interés mostrado por disciplinas económicas como la Nueva Economía Institucional (NEI), sino que se han realizado numerosos y continuos trasplantes a lo largo de la historia. Es más, su origen, aunque incierto, se remonta, al menos, al Código de Hammurabi del siglo XVII a.C. 
La literatura jurídica sobre trasplantes prácticamente se ha visto reducida a una lucha entre transferistas, con una visión más optimista del tema, y culturalistas, que lo enfocan desde un punto de vista más pesimista. Estamos de acuerdo con los culturalistas en que, la mayoría de las veces, la norma está vinculada a un contexto socioeconómico determinado, es decir, está hecha para un país y unos ciudadanos concretos. Sin embargo, aunque eso podría dificultar el trasplante, no por ello lo hace imposible. El fracaso de determinados trasplantes no implica que no puedan ser un éxito si se hacen de una manera más flexible y eficaz.

Creemos que los estudios sobre trasplantes legales expuestos en este artículo, que se remontan a los años 70 del siglo XX y que han sido llevados a cabo, sobre todo, por representantes de la disciplina de Derecho comparado, pueden aportar mayor luz a los autores de la NEI en su análisis de la relación entre las instituciones y el desempeño económico y en su búsqueda de las causas del crecimiento. También son una gran aportación al análisis de los resultados de la política de condicionalidad de las instituciones financieras internacionales, como el Banco Mundial o el Fondo Monetario Internacional, ya que los préstamos que llevan aparejadas condiciones, en forma de reformas o trasplantes institucionales, no han logrado, salvo excepciones muy concretas y localizadas, generar crecimiento económico sostenido.

En teoría, el trasplante de normas prestigiosas que funcionan muy bien en otros países, en particular normas relativas a la protección de los derechos de propiedad, la garantía del cumplimiento de los contratos, la liberalización de los mercados y la estabilidad macroeconómica, debería producir un crecimiento económico en el país receptor, ya que incentiva la inversión y la actividad empresarial. De lo que se trata es de coger normas que son consideradas buenas para la economía de los países en los que se originan e implantarlas en países con pobres resultados económicos para mejorar su desempeño. Esta es una buena hipótesis que debe convertirse en el punto de partida para que economistas de la NEI y de otras disciplinas de la economía se planteen realizar más estudios sobre la utilidad de los trasplantes de instituciones.

El principal problema es que si estas nuevas instituciones chocan con el contexto social $-\mathrm{y}$ político-, la cultura o las tradiciones del país receptor, el trasplante no producirá ningún efecto. Los ciudadanos a los que debe aplicarse la nueva norma -o conjunto de normas- no la cumplirán porque su costumbre es otra. Aquí entra en juego el concepto de path dependence o "dependencia de la trayectoria". Y es que, una vez que en una sociedad se arraigan unas creencias, valores o tradiciones, es difícil salirse del camino que éstos han marcado. No obstante, como apuntan ciertos autores, no es imposible. Algunos creemos que una sociedad puede cambiar sus tradiciones incluso de una generación a otra.

Además, a nuestro juicio, el obstáculo generado por el path dependence no es tan insalvable como el que supone que un país esté regido por una élite a la que beneficie un marco institucional ineficaz. Si tener malas instituciones beneficia a los gobernantes, entonces un trasplante de normas o prácticas más democráticas o aperturistas no será bien recibido, máxime si ese trasplante no es voluntario, sino que, como suele ocurrir en estos casos, viene impuesto por una agencia internacional.

La mayoría de los autores proponen, para solucionar el problema de incompatibilidad que surge en algunos trasplantes, la adaptación de la nueva norma a la sociedad huésped, realizando los cambios que sean necesarios. Tras estos ajustes, la norma lógicamente no será la misma, pero los autores creen que se puede calificar ese trasplante como exitoso. La flexibilidad es, por tanto, tremendamente importante. Creemos que se deben hacer en la norma todas las variaciones que hagan falta para que se adapte a las nuevas condiciones y a las nuevas personas a las que va dirigida.

Lo que está claro es que, tras décadas de intensas investigaciones, aún no sabemos utilizar los trasplantes como medio para lograr crecimiento. Por eso y porque, como decía Watson, los trasplantes son inevitables -y más aún en la sociedad globalizada de hoy en día-, es necesario realizar muchos más estudios sobre este tema, ya sea en el campo del Derecho o en el de la economía, para llegar a mejores conclusiones que permitan adoptar otras estrategias para aprovechar esta fantástica herramienta. 


\section{Bibliografía}

Acemoglu, Daron; Johnson, Simon y Robinson, James A. 2005. Institutions as the Fundamental Cause of Long-Run Growth. En Aghion, Philippe y Durlauf, Steven (eds.), Handbook of Economic Growth., vol. IA, cap. 6, 386- 464. http://economics.mit.edu/files/4469

Acemoglu, Daron y Robinson, James A. 2012. Por qué fracasan los países. Barcelona, Deusto. Berkowitz, Daniel; Pistor, Katharina y Richard, Jean-Françoise. 2003. Economic Development, Legality, and the Transplant Effect, European Economic Review, vol. 47, 165-195. http://www.columbia.edu/ kp2022/Articles/8)\%20EER\%202003.pdf

- 2003. The Transplant Effect, The American Journal of Comparative Law. American Society of Comparative Law, winter, vol. 51 (1), 163-203.

http://www.columbia.edu/ kp2022/Articles/7)\%20AJCL\%202003.pdf

Bonilla Maldonado, Daniel. 2009. Teoría del Derecho y trasplantes jurídicos. Bogotá, Siglo del Hombre. http://diegolopezmedina.net/wp-content/uploads/2014/03/dos-libros.pdf

Burnside, Craig and Dollar, David. 2000. Aid, Policies, and Growth, The American Economic Review. American Economic Association, september, vol. 90 (4), 847-868. http://www.hec.unil.ch/ocadot/SECODEVdocs/Articles/Burnside-Dollar.pdf

Cohn, Margit. 2010. Legal Transplant Chronicles: The Evolution of Unreasonableness and Proportionality Review of the Administration in the United Kingdom, American Journal of Comparative Law. American Society of Comparative Law, may, vol. 58 (3), 583-629. http://papers.ssrn.com/sol3/papers.cfm?abstract_id=1619864

Easterly, William. 2003. En busca del crecimiento. Andanzas y tribulaciones de los economistas del desarrollo. Barcelona, Antoni Bosch.

-- 2003. Can Foreign Aid Buy Growth? Journal of Economic Perspectives. American Economic Association, summer, vol. 17 (3), 23-48.

https://williameasterly.files.wordpress.com/2010/08/40_easterly_canforeignaidbuygrowth_pr p.pdf

- 2005. What did structural adjustment adjust? The association of policies and growth with repeated IMF and World Bank adjustment loans, Journal of Development Economics, february, vol. $76(1), 1-22$.

http://www.development.wne.uw.edu.pl/uploads/Courses/dev_easterly_2006.pdf

- 2009. Can We West Save Africa? Journal of Economic Literature. American Economic Association, june, vol. 47 (2), 373-447. (NBER Working Paper 14363, September 2008). http://www.nber.org/papers/w14363.pdf

Easterly, William; Levine, R. and Roodman, D. 2004. New data, new doubts: A Comment on Burnside and Dollar's "Aid, Policies, and Growth" (2000), American Economic Review. American Economic Association, june, vol. 94 (3), 774-780. (NBER Working Paper num. 9846, 2003). http://www.nber.org/papers/w9846.pdf

Eggertsson, Thrainn. 2005. ¿Por Qué Fracasan a Menudo los Transplantes Institucionales? Revista Asturiana de Economía, 32, 9-21. http://www.revistaasturianadeeconomia.org/raepdf/32/eggertssonRae32.pdf

Ewald, William. 1995. Comparative Jurisprudence (II): The Logic of Legal Transplants, The American Journal of Comparative Law. American Society of Comparative Law, autumn, vol. 43 (4), 489-510. http://www.jstor.org/stable/840604

Kahn-Freund, Otto. 1974. On Uses and Misuses of Comparative Law, The Modern Law Review. january, vol. 37 (1),1-27. http://onlinelibrary.wiley.com/doi/10.1111/j.1468-2230.1974.tb02366.x/epdf

Kassahun, Yohannes. 2006. Epilogue: An Overview of The Law Reform in the Economic Development Context. En McInerney, Thomas F. (ed.), Searching for Success. Narrative Accounts of Legal Reform in Developing and Transition Countries, International Development Law Organization. Legal and Governance Reform: Lessons Learned num. 1. http://www.ebrd.com/downloads/legal/what/idlo.pdf 
La Porta, Rafael; López-de-Silanes, Florencio; Shleifer, Andrei y Vishny, Robert. 1998. Law and Finance, Journal of Political Economy. The University of Chicago, vol. 106 (6), 11131155. (NBER Working Paper 5661, 1996).

https://www.hse.ru/data/106/482/1225/Sept\%209\%20Law\%20and\%20Finance.pdf http://www.nber.org/papers/w5661.pdf

- 1999. The Quality of Government. Journal of Law, Economics, and Organization, april, vol. 15 (1), 222-279. (NBER Working Paper 6727, september 1998).

http://www.nber.org/papers/w6727.pdf

Legrand, Pierre. 1997. The Impossibility of legal transplants, Maastricht Journal of European and Comparative Law, vol. 4 (2), 111-124.

http://www.pierrelegrand.com/transplants.pdf 1/03/2015.

Mamadouh, Virginie; De Jong, Martin y Lalenis, Konstantinos. 2003. An Introduction to Institutional Transplantation, Discussion Paper Series, University of Thessaly, march, vol. 9 (13), pp. 273-292. http://www.prd.uth.gr/uploads/discussion_papers/2003/uth-prd-dp-2003-13_en.pdf

Mattei, Ugo. 1994. Efficiency in Legal Transplants: an Essay in Comparative Law and Economics, International Review of Law and Economics, march, vol. 14 (1), p. 3-19. $\mathrm{http}: / /$ works.bepress.com/cgi/viewcontent.cgi?article=1013\&context=ugo_mattei

Miller, Jonathan M. 2005 [2003]. Una Tipología de los Trasplantes Legales: Utilizando la Sociología, la Historia del Derecho y Ejemplos Argentinos Para Explicar el Proceso de Trasplante, Lecciones y Ensayos, 81, 17. Artículo original: A Typology of Legal Transplants: Using Sociology, Legal History and Argentine Examples to Explain the Transplant Process, The American Journal of Comparative Law, American Society of Comparative Law, autumn, vol. $51(4), 839-885$.

http://www.Derecho.uba.ar/publicaciones/lye/revistas/81/una-tipologia-de-los-transplanteslegales.pdf

Montaner, Josep María. 2007. Microcréditos trasplantados. En El País, ed. impresa de 15 de marzo de 2007. http://elpais.com/diario/2007/03/15/catalunya/1173924442_850215.html

Olson, Mancur. 2007 [1996]. Billetes Grandes Tirados en la Acera: de Cómo Algunas Naciones son Ricas y Otras Pobres. En Desarrollo: crónica de un desafío permanente. Universidad de Granada, -110. Artículo original "Big Bills Left on the Sidewalk: Why Some Nations are Rich, and Other Poor?” Journal of Economic Perspectives, spring, vol. 10 (2), 3-24. http://fbird.com/assets/MancurOlson_on_Transition_Econ_732003152238.pdf

Örücü, Esin. 2000. Critical Comparative Law: Considering Paradoxes for Legal Systems in Transition, Electronic Journal of Comparative Law, june, vol. 4.1. http://www.ejcl.org/41/abs41-1.html

Reyes Gaitán, María Paula. 2014. "The challenges of Legal Transplants in a Globalized Context: A Case Study on 'Working' Examples". October. http://papers.ssrn.com/sol3/papers.cfm?abstract_id=2530811

Rodrik, Dani. 1997. "Democracy and Economic Performance". Harvard University. A paper for a conference in South Africa. December. http://www.ueh.edu.vn/userfiles/file/demoecon.pdf

- 2000. Institutions for high-quality growth: What they are and how to acquire them, Studies in Comparative International Development, fall, vol. 35 (3), 3-31. NBER Working Paper num. 7540. http://www.nber.org/papers/w7540.pdf

- 2000. Participatory Politics, Social Cooperation, and Economic Stability, The American Economic Review. Papers and Proceedings of the One Hundred Twelfth Annual Meeting of the American Economic Association, may, vol. 90 (2), 140-144.

https://www.sss.ias.edu/files/pdfs/Rodrik/Research/participatory-politics-socialcooperation.PDF

Rodrik, Dani y Subramanian, Arvind. 2003. La primacía de las instituciones (y lo que implica), Finanzas y Desarrollo. Fondo Monetario Internacional, junio, 31-34.

https://www.imf.org/external/pubs/ft/fandd/spa/2003/06/pdf/rodrik.pdf 
Sacco, Rodolfo. 1991. Legal Formants: A Dynamic Approach to Comparative Law, The American Journal of Comparative Law. American Society of Comparative Law, vol. 49, 1-34/343401. http://www.uniheidelberg.de/institute/fak2/mussgnug/historyoftaxdocuments/schrifttum/aufs aetze/AUFS00030.pdf

Siems, Mathias M. 2014. The Curious Case of Overfitting Transplants. En Adams, Maurice and Heirbaut, Dirk (eds)The Method and Culture of Comparative Law: Essays in Honour of Mark Van Hoecke. Oxford, Hart Publishin May, 133-146. http://papers.ssrn.com/sol3/papers.cfm?abstract_id=2437402

Smith, Alastair. 2005. Why International Organizations will continue to fail their development goals, Perspective on Politics, august, vol. 3 (3), 565-567. http://www.nyu.edu/gsas/dept/politics/faculty/smith/PerspectiveOnPolitics2005.pdf

Svensson, Jakob. 2003. Why Conditional Aid Doesn't Work and What Can Be Done About It? Journal of Development Economics, april, vol. 70 (2), 381-402. http://papers.ssrn.com/sol3/papers.cfm?abstract_id=428901

Teubner, Gunther. 1998. Legal Irritants: Good Faith in British Law or How Unifying Law Ends Up in New Differences, The Modern Law Review. Blackwell Publishers, january, vol. 61, 1132.m file:///D:/Perfil\%20Usuario/sbc10/Commadri/Downloads/SSRN-id876950\%20(1).pdf

Twining, William. 2004. Diffusion of Law: A Global Perspective, The Journal of Legal Pluralism and Unofficial Law, vol. 36 (49), 1-45.

http://cscs.res.in/dataarchive/textfiles/textfile.2009-08-20.0046090122/file

Watson, Alan. 1993 [1974]. Legal transplants: An Approach to Comparative Law, Second Edition. Georgia, University of Georgia Press.

- 2000. Legal Transplants and European Private Law, Electronic Journal of Comparative Law. December, vol. 4.4. http://www.ejcl.org/44/art44-2.html http://www.alanwatson.org/legal_transplants.pdf 